peritoneal cancer and lung cancer each recorded 1 (1.5\%) case. In most cases bilateral disease was present (43 cases, $67.2 \%)$, while surface involvement was recorded in 55 patients (86\%). Survival data existed only for a subset of 15 patients with median overall survival of 23.7 months $(95 \%$ CI12.7-34.8).

Conclusion* Metastatic ovarian cancer is more usually seen from primary gastric, breast and colon cancer. Hematogenous spread appears a more common route in these cases, rather than transserosal pathway. Despite survival data were limited in a subset of patients, data indicate the presence of long-term survivors. Analysis of larger datasets is warranted to optimize surgical and medical treatment in patients with metastatic disease to the ovary.

\section{CORRELATIVE ANALYSES OF PHASE 1B STUDY OF NAVICIXIZUMAB PLUS PACLITAXEL IN PATIENTS WITH PLATINUM RESISTANT OVARIAN CANCER USING XERNATM TME PANEL}

${ }^{1} \mathrm{~K}$ Moore ${ }^{*},{ }^{2} \mathrm{~K}$ Culm-Merdek, ${ }^{2} \mathrm{C}$ Mockbee, ${ }^{2} \mathrm{H}$ Youssoufian, ${ }^{2} \mathrm{~V}$ Chamberlain Santos, ${ }^{3} \mathrm{R}$ Rosengarten, ${ }^{2} \mathrm{~L}$ Benjamin, ${ }^{4} \mathrm{~S}$ Fu. ${ }^{1}$ University of Oklahoma Health Sciences Center, Oklahoma City, USA; ${ }^{2}$ OncXerna Therapeutics, Inc., Waltham, USA; ${ }^{3}$ Genialis, Boston, USA; ${ }^{4} \mathrm{MD}$ Anderson Cancer Center, Houston, USA

\subsection{6/ijgc-2021-ESG0.49}

Introduction/Background* No biomarkers have been established yet to predict response to anti-angiogenic treatment. To test whether the Xerna ${ }^{\mathrm{TM}}$ TME Panel, a novel biomarker, is predictive of anti-angiogenic treatment outcome, an exploratory, retrospective analysis of the Phase $1 \mathrm{~b}$ study of navicixizu$\mathrm{mab}$ in combination with paclitaxel in platinum resistant ovarian cancer was performed. Navicixizumab is a bispecific anti-angiogenic antibody to vascular endothelial growth factor (VEGF) and delta-like ligand 4. The Xerna ${ }^{\mathrm{rm}}$ TME Panel evaluates RNA gene expression data of $\sim 100$ genes defining the immune and angiogenic biologies that dominate the tumor microenvironment (TME). This novel diagnostic employs a machine learning model to classify a patient's TME along immune and angiogenic axes, resulting in classification into one of four TME subtypes-Angiogenic (A), Immune Suppressed (IS), Immune Active (IA) and Immune Desert (ID). We hypothesized that patient TME subtypes classified with angiogenic dominant biology (A/IS) are more likely to benefit from treatment with navicixizimab relative to those in the biomarker negative subgroup (IA/ID).

Methodology The Phase $1 \mathrm{~b}$ study of navicixizumab $(3 \mathrm{mg} / \mathrm{kg}$ or $4 \mathrm{mg} / \mathrm{k}, \mathrm{IV}, \mathrm{q} 2 \mathrm{w})$ in combination with paclitaxel $\left(80 \mathrm{mg} / \mathrm{m}^{2}\right.$ IV on D0, D7, and D14 of 28-day cycle) was an open-label, non-randomized study that included 44 patients with platinum-resistant, grade $2 / 3$ ovarian cancer. Patients received a median of 4 prior treatments (63\% prior bevacizumab, $45 \%$ prior PARP). Pre-treatment tumor tissue was analyzed retrospectively using the Xerna ${ }^{\mathrm{TM}}$ TME Panel.

Result(s)* The objective response rate per RECIST 1.1 was $43.2 \%$ in the overall patient population $(n=44)$. Responses were durable (median 6 months [95\% CI, 5.4 months, not estimable]). Pre-treatment tumor tissue was available for 33 patients. In the B-positive subgroup (A/IS, $n=13), 62 \%$ of patients had an objective response, compared to $25 \%$, in the B-negative subgroup (IA/ID, $\mathrm{n}=20$ ). PFS was 9.2 months in the B-positive subgroup vs. 3.9 months in the B-negative subgroup, $\mathrm{HR}=0.43$ [95\% CI 0.188 to 0.999$]$ ).
Conclusion* Navicixizumab plus paclitaxel demonstrated promising clinical activity in this heavily pretreated patient population. The Xerna ${ }^{\mathrm{TM}}$ TME Panel may identify patients more likely to benefit from treatment with navicixizumab and should be prospectively evaluated in a future study.

\section{LONG TERM FOLLOW-UP OF A LARGE SERIES OD STAGE II/III SEROUS OVARIAN BORDERLINE TUMORS}

S Gouy*, S Maria, A Maulard, M Faron, A Leary, P Pautier, C Chargari, C Generstie, P Morice. Gustave Roussy, Villejuif, France

\subsection{6/ijgc-2021-ESG0.492}

Introduction/Background* The aim of this study was to assess prognostic factors and implications on further management in a large series of stage-II or III Serous Borderline Ovarian Tumors (SBOTs) with a long-term follow-up.

Methodology Patients with SBOTs and peritoneal implants treated in, or referred to, our institution were retrospectively reviewed. Prognostic factors on invasive recurrence, diseasefree (DFS) and overall survival (OS) were analyzed.

Result(s)* Between 1971 and 2017, 212 patients were identified and followed (33 having invasive implants). After a median follow-up of 115 months, 70 recurrences were observed, 28 of them under the form of invasive disease. DFS at 5 years and 10 years was $73 \%$ and $62 \%$ respectively. The use of a conservative treatment $(\mathrm{HR}=5.5[3.33-9.08], \mathrm{p}<.0001)$, the presence of $\geq 3$ peritoneal sites with implants $(\mathrm{HR}=1.65$ [1.01-2.72], $\mathrm{p}=.045)$ were unfavorable prognostic factors for DFS. The presence of $\geq 3$ peritoneal sites with implants $(\mathrm{HR}=3.02[0.96$ 9.53], $\mathrm{p}=.049)$ and the presence of stromal microinvasion $(\mathrm{HR}=3.19$ [1.12-9.1], $\mathrm{p}=.022)$ were unfavorable prognostic factors for OS. Non-conservative surgery $(\mathrm{HR}=7[2.35-20.87]$, $\mathrm{p}=0.0002)$, invasive implants $(\mathrm{HR}=5.37[1.29-22.26], \mathrm{p}=0.013)$, and $\geq 3$ peritoneal sites with implants $(\mathrm{HR}=3.56$ [1.11-11.39], $\mathrm{p}=0.024)$ were identified as predictors of recurrence in the form of an invasive disease. Invasive implants were not associated with DFS $(\mathrm{HR}=1.39[0.77-2.51], \quad \mathrm{p}=0.27)$, nor $\mathrm{OS}$ $(\mathrm{HR}=1.76[0.57-5.47], \mathrm{p}=0.32)$.

Conclusion* After a long-term follow-up, type of peritoneal implants is no longer a prognostic factor for OS. Implants $\geq$ 3 peritoneal sites seem to impact significantly OS and then require a specific follow-up in this subgroup of patients.

\section{SURVIVAL IN ADVANCED STAGE EPITHELIAL OVARIAN CANCER PATIENTS WITH CARDIOPHRENIC LYMPHADENOPATHY WHO UNDERWENT CYTOREDUCTIVE SURGERY: A META-ANALYSIS}

\begin{abstract}
${ }^{1,2} \mathrm{M}$ Kengsakul ${ }^{*},{ }^{1,3} \mathrm{G}$ Nieuwenhuyzen-de Boer, ${ }^{4} \mathrm{~A}$ Bijleveld, ${ }^{5} \mathrm{~S}$ Udomkarnjananun, ${ }^{5} \mathrm{~S}$ Kerr, ${ }^{6} \mathrm{C}$ Niehot, ${ }^{1} \mathrm{HJ}$ Van Beekhuizen. ${ }^{1}$ Erasmus University Medical Center, Gynaecological Oncology, Rotterdam, Netherlands; '2Panyananthaphikkhu Chonprathan Medical Center, Srinakharinwirot University, Gynaecological Oncology, Nonthaburi, Thailand; ${ }^{3}$ Albert Schweitzer Hospital, Gynaecological Oncology, Dordrecht, Netherlands; ${ }^{4}$ Albert Schweitzer Hospital, Obstetric and Gynaecology, Dordrecht, Netherlands; ${ }^{5}$ King Chulalongkorn Memorial Hospital, Bangkok, Thailand; ${ }^{6}$ Erasmus University Medical Center, Medical Library, Rotterdam, Netherlands
\end{abstract}

\subsection{6/ijgc-2021-ESG0.493}

Introduction/Background* Favourable survival outcomes for patients with advanced stage ovarian cancer are associated 